\title{
The development of an alcohol brief intervention e-coach for use by primary care clinicians
}

\author{
Lauren M Broyles ${ }^{1 *}$, Manu Singh², Keri Rodriguez ${ }^{1}$, Susan Hayashi², Bob Monte ${ }^{1}$, Adam Gordon \\ From International Network on Brief Interventions for Alcohol and Other Drugs (INEBRIA) Meeting 2013 \\ Rome, Italy. 18-20 September 2013
}

\section{Introduction}

Rates of drinking, binge drinking, and driving under the influence of alcohol are higher among U.S. Veterans than non-Veterans, and approximately $20 \%$ to $30 \%$ of all U.S. Veterans screen positive for alcohol misuse ranging from risky drinking to alcohol dependence. To address these serious concerns, the U.S. Department of Veterans Affairs (VA) policies and clinical practice guidelines standardize expectations for alcohol SBI and provide clinical decisionmaking guidance. However, there are key provider-level barriers to BI uptake and implementation including (1) lack of alcohol BI knowledge and skills and (2) competing clinical priorities for limited available time. Rates of BI delivery by busy primary care clinicians are low, even when prompted by electronic reminders based in the VA's electronic medical record. Currently, BI training and practical role supports are not systematically offered.

\section{Objective}

The purpose of this project was to develop and assess user feedback on a computerized clinical decision support system (CCDSS) to assist primary care clinicians with the real-time delivery and documentation of alcohol BI delivery. We (1) systematically assessed primary care clinicians' processes and preferences of alcohol-related care to inform the development of a CCDSS and (2) developed the BI E-Coach CCDSS and assessed its usability, feasibility, and acceptability among clinician stakeholders in primary care.

\section{Methods}

We conducted on-site semi-structured interviews, observations, and surveys with key sets of primary care staff members before and after pilot testing the BI-E-Coach

\footnotetext{
* Correspondence: Lauren.Broyles@va.gov

'VA Pittsburgh Healthcare System, Pittsburgh, PA, USA

Full list of author information is available at the end of the article
}

tool, to facilitate its development, and to assess its usability, feasibility, and acceptability.

\section{Results}

E-coach prototype development is described in the contexts of primary care work flow, processes of alcohol-related care, and clinician preferences regarding the utility, feasibility, and acceptability of the BI-E-Coach. Additionally, initial implementation barriers, facilitators, and efficacy are reported.

\section{Discussion}

Refinement of the E-coach, efficacy testing, and implications for implementation are discussed.

\section{Authors' details \\ ${ }^{1}$ VA Pittsburgh Healthcare System, Pittsburgh, PA, USA. ${ }^{2}$ JBS International, Inc., North Bethesda, MD, USA.}

Published: 4 September 2013

doi:10.1186/1940-0640-8-S1-A15

Cite this article as: Broyles et al:: The development of an alcohol brief intervention e-coach for use by primary care clinicians. Addiction Science \& Clinical Practice 2013 8(Suppl 1):A15.

Submit your next manuscript to BioMed Central and take full advantage of:

- Convenient online submission

- Thorough peer review

- No space constraints or color figure charges

- Immediate publication on acceptance

- Inclusion in PubMed, CAS, Scopus and Google Scholar

- Research which is freely available for redistribution
C Biomed Central

C 2013 Broyles et al; licensee BioMed Central Ltd. This is an Open Access article distributed under the terms of the Creative Commons Attribution License (http://creativecommons.org/licenses/by/2.0), which permits unrestricted use, distribution, and reproduction in any medium, provided the original work is properly cited. 